\title{
Knowledge Attitude and Practice towards Infection Control Measures amongst Medical Students in a Medical Teaching Tertiary Care Hospital
}

\author{
Keshvi Chauhan \\ Government Medical College, Surat, India \\ Email: drsangitarajdev@gmail.com
}

How to cite this paper: Chauhan, K. (2017) Knowledge Attitude and Practice towards Infection Control Measures amongst Medical Students in a Medical Teaching Tertiary Care Hospital. International Journal of Clinical Medicine, 8, 534-542. https://doi.org/10.4236/ijcm.2017.89050

Received: August 11, 2017

Accepted: September 26, 2017

Published: September 29, 2017

Copyright $\odot 2017$ by author and Scientific Research Publishing Inc. This work is licensed under the Creative Commons Attribution International License (CC BY 4.0).

http://creativecommons.org/licenses/by/4.0/ (c) (i) Open Access

\begin{abstract}
Introduction: Health care associated infections (HAIs) are likely to be the most common complication of hospital care. World Health Organization (WHO) estimates these infections to occur among $7 \%-12 \%$ of the hospitalized patients globally, with more than 1.4 million people suffering from infectious complications acquired in the hospital at any time. Keeping this in mind, the present study was conducted to delineate the level of knowledge, attitudes, and practices (KAP) for the use of proper disinfection procedures among the final year undergraduate medical students in a tertiary care hospital and teaching institute. Methodology: Present study was conducted at Government Medical College, Surat, a tertiary care hospital and teaching institute. The participants who gave consent were provided with a pre-tested questionnaire that included several questions on knowledge attitude and practices on hospital acquired infections and its control practices. Analysis of the answers was done based on KAP score. Result: 80 students who consented were included in the study. $75 \%$ of the study population had correct knowledge about the most common health care associated infections (HAIs), being infection of venous access, urinary tract infection, respiratory infections and surgical site infections, based on their current knowledge on hospital acquired infections. Majority of study participants agreed with the fact that the inappropriate application of disinfection procedures increases the risk for a health care worker of either acquiring or transmitting a HAI from/to a patient. $>90 \%$ participants had a good attitude towards risk of getting or transmitting any infectious disease by a Health care worker (HCW) while working and the utility of the application of disinfection procedures during work would reduce the rates of HAI. Practices of the students towards disinfection during performance of
\end{abstract}


certain medical procedures ranged from $10 \%$ to $88 \%$ of the times showing poor practices of the medical students in following disinfection practices. Conclusion: In the present study the knowledge of medical students for the most common cause of hospital acquired infection was satisfactory. The overall attitude of the students was satisfactory as the mean score was 8 . The practices of the students for the application of disinfection during performance of certain medical procedures were also satisfactory, although time to time training and tutorials of these students can help in increasing their knowledge, attitude and practices.

\section{Keywords}

Hospital Acquired Infection, Medical Students, Knowledge Attitude and Practices (KAP) Score

\section{Introduction}

Healthcare associated infection, alternatively also called "hospital acquired infection" (HAI), or "nosocomial infection" refers to the infection occurring in patients after admission at the hospital for a reason other than that infection; an infection that was neither present nor incubating at the time of admission. This includes infections acquired in the hospital but appearing during hospital stay or after discharge, and also occupational infections among staff of the facility [1] [2] [3]. As a general timeline, infections occurring more than 48 hours after admission are usually considered hospital acquired. The Hospital Infection Society of India (HISI) finds the latter justified in the Indian scenario, as most of the time it is difficult to make out whether an infection was acquired outside the hospital or inside a specific healthcare set-up [4]. HAIs are likely to be the most common complication of hospital care. World Health Organization (WHO) estimates these infections to occur among $7 \%-12 \%$ of the hospitalized patients globally, with more than 1.4 million people suffering from infectious complications acquired in the hospital at any time [1] [2] [5]. Moreover, the burden of HAIs is higher in developing countries [6]. In 2007, the INICC conducted a prospective surveillance in 7 Indian cities to determine the rate of HAI. An overall HAI incidence rate of $4.4 \%$ corresponding to 9.06 infections per 1000 ICU-days was reported [7]. Lately, there are increasing reports from different parts of the country revealing varying HAI incidence rates across various healthcare setups. HAIs account for major causes of death, functional disability, emotional suffering and economic burden among the hospitalized patients [2] [3]. The increased length of stay for infected patients is the greatest contributor to cost. The increased use of drugs, the need for isolation, and the use of additional laboratory and other diagnostic studies also contribute to costs. In India, the extravagant use of antibiotics and antibiotic resistance adds to the expenditure as well as mortality following HAI [8]. Additionally, in India, infections due to multi drug resistant 
organisms increase mortality and also warrant the use of high end antibiotics like Carbapenems and new generation Tetracyclines which increase the health care expenditure [3].

Keeping the above aspects in mind, the present study was conducted to delineate the level of knowledge, attitudes, and practices for the use of proper disinfection procedures among the final year undergraduate medical students in a tertiary care hospital and teaching institute. The students regularly attended the in-patient and out-patient clinics along with operation theatres, so assessment of their knowledge, attitudes, and practices for HAI is of crucial importance.

\section{Material and Method}

The present study is a cross sectional study that included 80 final years under graduate medical students, regularly attending in-patient and out-patient clinics along with operation theatres. It was conducted at tertiary care hospital and teaching institute after ethical clearance. Selection was done on random basis and identities of participants were decoded. The participants who gave consent were provided with a pre-tested questionnaire that included several questions on knowledge attitude and practices on hospital infection prevention, skin disinfection and hand washing, waste disposal, universal precautions and nosocomial infection. Each of the fields was given a score, the KAP score. The questionnaire was designed such that it included a series of items divided in the following sections: 1) knowledge about the frequency of the HAIs and the disinfection practices; 2) attitudes towards the utility of guidelines/protocols and perception of the risks of acquiring or transmitting HAIs; 3 ) practices and behaviors with antisepsis/disinfection procedures; and 4) sources most frequently used to receive up-to-date information about disinfection procedures. The series of answers to the knowledge questions about disinfection practices were arranged by asking respondents to indicate their agreement with true or false statements on a three point Likert-type scale (i.e., agrees, uncertain, disagrees), and about the frequency of the HAIs were as "yes" and "no" choices. Responses to all items assessing attitudes evaluated relating level of agreement or disagreement were on a ten-point Likert-type scale ranging from "1" to "10", meaning "not likely at all" and "very likely" for the two questions on the perceived risk for a HCW to acquire from a patient or to transmit to a patient a HAI and for the question towards the utility of guidelines/protocols for disinfection procedures meaning "not at all" and "very much". Responses to all items assessing the behaviors evaluated whether or not they perform antisepsis/disinfection procedures in their working activity were as "yes" and "no" choices. All data were added to Microsoft excel sheet and percentages of different responses were analyzed.

\section{Result}

80 participants who consented were included in the study. All the participants were final year MBBS undergraduate students who regularly attended the in-patient 
and out-patient clinics along with operation theatres as a part of their clinical teaching curriculum. In the present study, participants had good knowledge and attitude but poor practices towards different aspects of hospital acquired infections and its control measures.

$75 \%$ (60 participants) of the study population had correct knowledge about the most common HAIs being infection of venous access, urinary tract infection, respiratory infections and surgical site infections, based on their current knowledge on hospital acquired infections as shown in Table 1 . Also about $94 \%$ of the participants correctly knew that the inappropriate application of disinfection procedures increases the risk for a health care worker of either acquiring or transmitting a $\mathrm{HAI}$ from/to a patient.

The percentage of the respondents who had appropriate knowledge on the questions of most common HAIs and inappropriate disinfection causing HAI is shown in Table 1.

Attitudes towards the utility of guidelines/protocols for disinfection procedures, measured on a ten-point Likert scale ranging from 1 to 10 with higher scores indicating more positive attitudes as shown in Table 2. Responses from the study participants showed a mean score of 7 with the highest score being 9 and the lowest being 4 . $>90 \%$ participants had a good attitude towards risk of getting or transmitting any infectious disease by a HCW while working and the utility of the application of disinfection procedures during work would reduce the rates of HAI.

Practices of the students towards disinfection during performance of certain medical procedures ranged from $10 \%$ to $88 \%$ of the times (Table 3 ). $>80 \%$ of the participants practiced disinfection procedures during certain medical procedures like insertion venous catheter, urethral catheter and intramuscular or intravenous injections. $<50 \%$ answered that they followed disinfection procedures

Table 1. Table showing the percentage of the respondents who had appropriate knowledge on the questions of most common HAIs and inappropriate disinfection causing HAI.

\begin{tabular}{|c|c|c|}
\hline Sr. No & Question & $\begin{array}{l}\% \text { of favourable } \\
\text { response }\end{array}$ \\
\hline 1 & Which of the following are the most common HAIs? & 75 \\
\hline 2 & Disinfectant should be applied for the specified contact time. & 88 \\
\hline 3 & $\begin{array}{l}\text { Inappropriate disinfection procedures increase the risk of getting HAIs } \\
\text { among hospitalized patients. }\end{array}$ & 94 \\
\hline 4 & $\begin{array}{l}\text { Inappropriate disinfection procedures increase the risk of transmitting } \\
\text { HAIs among hospitalized patients. }\end{array}$ & 61 \\
\hline 5 & $\begin{array}{l}\text { Inappropriate disinfection procedures increase the risk of getting HAIs } \\
\text { among healthcare workers (HCWs). }\end{array}$ & 50 \\
\hline 6 & $\begin{array}{l}\text { Inappropriate disinfection procedures increase the risk of transmitting } \\
\text { HAIs among HCWs. }\end{array}$ & 66 \\
\hline 7 & $\begin{array}{l}\text { Alcohol-based hand-rubbing should be performed before manipulation of } \\
\text { intravenous devices or insertion of a urethral catheter. }\end{array}$ & 74 \\
\hline
\end{tabular}


Table 2. Table showing the attitude of the study population towards risk of the HCW in getting/transmitting an infectious disease while working and that application of disinfection procedures can reduce the HAI rates.

\begin{tabular}{clc}
\hline Sr. No. & \multicolumn{1}{c}{ Question } & $\begin{array}{c}\text { \% of respondents with } \\
\text { answer scale > 5 }\end{array}$ \\
\hline 1 & $\begin{array}{l}\text { How do you perceive your risk of getting an infectious disease } \\
\text { while working? }\end{array}$ & 94 \\
2 & $\begin{array}{l}\text { How do you perceive your risk of transmitting an infectious } \\
\text { disease while working? }\end{array}$ & 92 \\
3 & $\begin{array}{l}\text { How would you rate the utility of the application of } \\
\text { guidelines/procedures for disinfection procedures? }\end{array}$ \\
\hline
\end{tabular}

Table 3. Table showing the percentage frequency of disinfection practices followed during certain medical procedures.

\begin{tabular}{ccc}
\hline Sr. No. & Question & $\begin{array}{c}\text { Percentage (\%) disinfection } \\
\text { was performed }\end{array}$ \\
\hline 1 & Peripheral venous catheterization & 86 \\
2 & Insertion of a urethral catheter & 88 \\
3 & Biopsy & 31 \\
4 & Surgical wound care & 64 \\
5 & Intramuscular injection & 81 \\
6 & Blood culture collection & 25 \\
7 & Intravenous injection & 81 \\
8 & Intra-arterial injection & 10 \\
9 & Skin contamination with body fluids & 81 \\
10 & Contamination of working surfaces with body fluids & 65 \\
\hline
\end{tabular}

during certain medical procedures like while taking a biopsy, blood culture collection or during an intra-arterial injection. However the significant difference in the answers might be due to the fact that the study population in majority had final year MBBS undergraduate students who might not have performed/attended such above mentioned procedures. Analysis of Knowledge, Attitudes and practices are shown in Figure 1 \& Figure 2 of hospital acquired infections and infection control practices as answered by final year MBBS undergraduate students.

Figure 1 \& Figure 2 shows that KAP analysis of students revels that attitude towards infection control practices found well but because lack of knowledge, people are not able to perform right practices. Regular trainings and efforts to increase knowledge may work for control of health care associated infections.

\section{Discussion}

Health care-associated infections have long been recognized as crucial factors undermining the quality and outcomes of health care delivery. Developing 


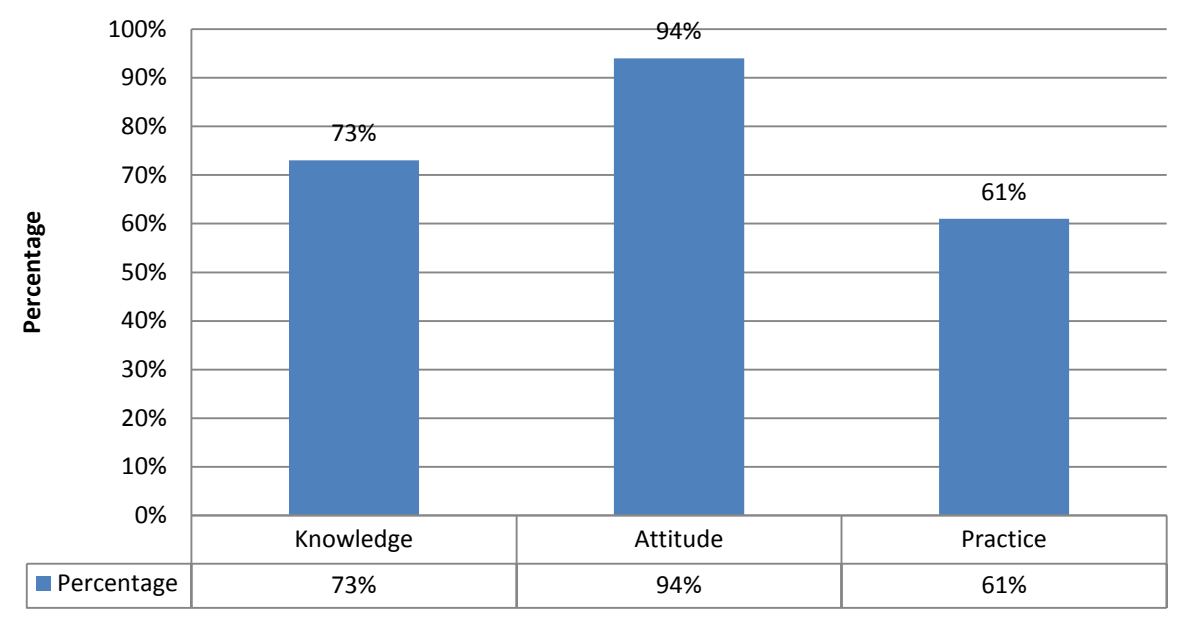

Figure 1. Average percentage of knowledge, attitude and practice in certain aspects of hospital acquired infections and infection control practices as answered by final year MBBS undergraduate students.

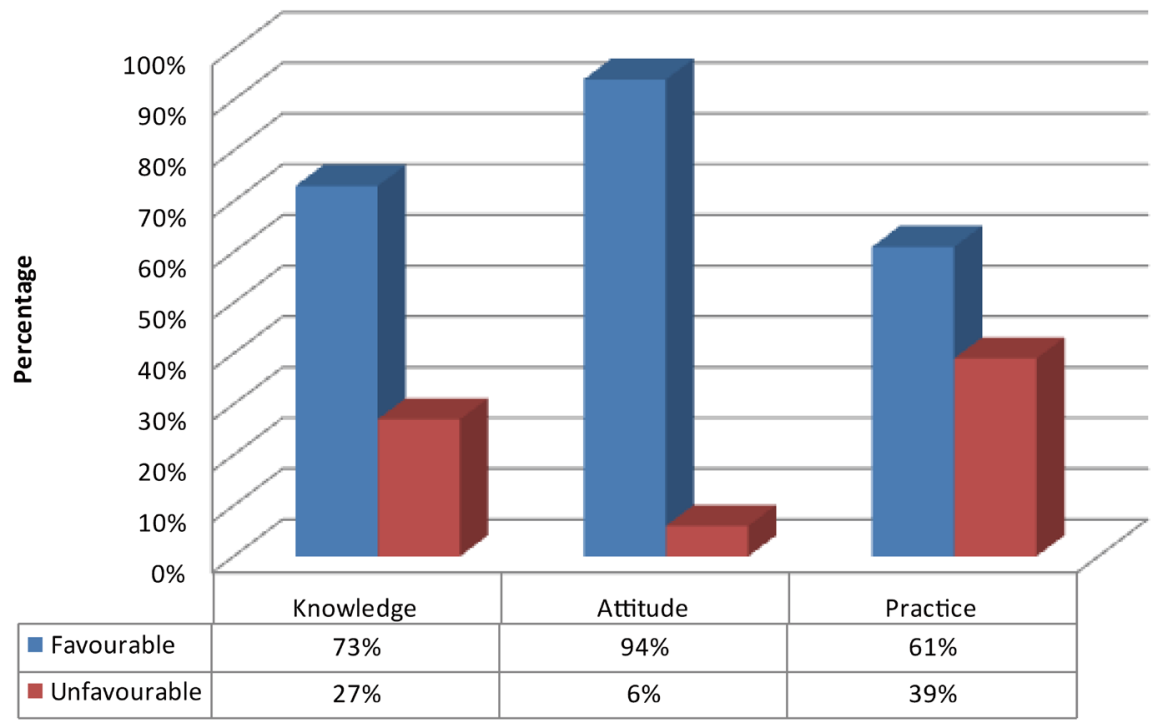

Figure 2. Average percentage of favorable and unfavorable responses in knowledge, attitude and practice towards certain aspects of hospital acquired infections and infection control practices as answered by final year MBBS undergraduate students.

countries were reported to have up to 20 times the risk of contracting a nosocomial infection compared to developed countries. Thus, spread of infection serves as a major source of worry for managers in health care practice, particularly in developing countries where the health care system is already overstretched [4].

Although infection is most prevalent in patients upon admission, health care workers also act as potential vectors for pathogenic agents. Hospitals provide a favorable transmission pathway for the spread of nosocomial infections, owing partly to poor infection control practices among health workers on one hand and overcrowding of patients in most clinical settings on the other. 
In the present study, participants had good knowledge and attitude but poor practices towards different aspects of hospital acquired infections and its control measures. $75 \%$ of the participants stated that the infection of venous access, urinary \& respiratory tract infections and infection of surgical site as the most common HAIs based on their current knowledge. Attitude towards the utility of guidelines/protocols for disinfection procedures was measured on a ten-point Likert scale ranging from 1 to 10 with higher scores indicating more positive attitudes. The overall attitude of the students was satisfactory as $>90 \%$ agreed for risk of getting or transmitting any infectious disease by a HCW while working and the utility of the application of disinfection procedures during work would reduce the rates of HAI. The practices of the students for the application of disinfection during performance of certain medical procedures were unsatisfactory. The practice of disinfection was inadequately followed during certain procedures like intra-arterial injections, biopsy, blood culture collection, etc. The reason behind this might be that the students were undergraduate final year medical students so they might not have attended or been able to do such procedures more frequently.

Information regarding to the newer/changing guidelines for infection control practices was given to the medical students by either their colleagues or other medical journals. $<50 \%$ participants had attended any educational course for disinfection during the past one year. So it would be better if there are regular workshops/seminars for the learning of newer guidelines as these undergraduate students are the future of clinical practice that need to be kept updated for their infection control practices.

Few studies have reported on medical student's knowledge of standard precautions or sharp injuries [9] [10] [11] and noted a lack of adequate knowledge of standard precautions [11]. In one survey, $27 \%$ of participating health care students reported insufficient emphasis on teaching about infection control in their training program, whilst 50\% expressed a desire for more emphasis on isolation procedures during their training [12]. Certain other studies [13] [14] have detected poor adherence to universal precautions among multiple health care providers. In a study by, it was found the general medical practitioners and medical college students had sufficient knowledge and attitude towards nosocomial infections. Also both these groups practice approach towards nosocomial infection was not sufficient and it needs improvement [15].

\section{Limitation}

As the study population contained majority of under graduate final year medical students, they lacked the practice of performing certain procedures like intra arterial injection, biopsy, blood culture collection, etc. Also if other health care workers like resident doctors or nursing staff would have been included in the study, it would have given more informative results as these HCWs are the ones who are in constant contact with the patients. 


\section{References}

[1] WHO (2002) Prevention of Hospital Acquired Infections. A practical Guide. 2nd Edition, WHO, Geneva.

http://www.who.int/csr/resources/publications/whocdscsreph200212.pdf

[2] Patel, D.A., Patel, K.B., Bhatt, S.K. and Shah, H.S. (2011) Surveillance of Hospital Acquired Infection in Surgical Wards in Tertiary Care Centre Ahmedabad, Gujarat. Nat J Commun Med, 2, 340-345.

[3] Chugh, T.D. (2012) Hospital Infection Control-Are We Serious? http://www.apiindia.org/pdf/medicine_update_2012/infectious_disease_14.pdf

[4] The Hospital Infection Society of India (HISI) (2007) Newsletter, Volume 3(2). http://hisindia.org/data/HISI-Aug07.pdf

[5] Saleem, M., et al. (2012) Prevalence of Nosocomial Infections in Surgical Wards of Tertiary Care Hospital at Lucknow. Indian Journal of Scientific Research, 3, 79-84.

[6] Allegranzi, B., Bagheri Nejad, S., Combescure, C., Graafmans, W., Attar, H., Donaldson, L., et al. (2011) Burden of Endemic Health-Care-Associated Infection in Developing Countries: Systematic Review and Meta-Analysis. Lancet, 377, 228-241. https://doi.org/10.1016/S0140-6736(10)61458-4

[7] Mehta, A., Rosenthal, V.D., Mehta, Y., Chakravarthy, M., Todi, S.K., Sen, N., et al. (2007) Device-Associated Nosocomial Infection Rates in Intensive Care Units of Seven Indian Cities. Findings of the International Nosocomial Infection Control Consortium (INICC). Journal of Hospital Infection, 67, 168-174. https://doi.org/10.1016/j.jhin.2007.07.008

[8] Ganguly, N.K., Arora, N.K., Chandy, S.J., Fairoze, M.N., Gill, J.P., Gupta, U., et al. (2011) Global Antibiotic Resistance Partnership (GARP)_India Working Group. Rationalizing Antibiotic Use to Limit Antibiotic Resistance in India. Indian Journal of Medical Research, 134, 281-294.

[9] Askarian, M., Honarvr, B., Tabatabaee, H.R. and Assadian, O. (2004) Knowledge, Practice and Attitude towards Standard Isolation Precaution in Iranian Medical Students. Journal of Hospital Infection, 58, 292-296.

https://doi.org/10.1016/j.jhin.2004.07.004

[10] Mann, C.M. and Wood, A. (2006) How Much Do Medical Students Know about Infection Control? Journal of Hospital Infection, 64, 366-370. https://doi.org/10.1016/j.jhin.2006.06.030

[11] Koenig, S. and Chu, J. (1993) Senior Medical Students Knowledge of Universal Precautions. Academic Medicine, 68, 372-374. https://doi.org/10.1097/00001888-199305000-00021

[12] Suchitra, J.B. and Lakshmidevi, N. (2007) Impact of Education on Knowledge, Attitudes and Practices among Various Categories of Health Care Workers on Nosocomial Infections. Indian Journal of Medical Microbiology, 25, 181-187. https://doi.org/10.4103/0255-0857.34757

[13] Angtuaco, T.L., Oprescu, F.G., Lal, S.K., Pennington, J.H., Russell, B.D., Co, J.M., et al. (2003) Universal Precautions Guideline: Self-Reported Compliance by Gastroenterologists and Gastrointestinal Endoscopy Nurses-A Decade's Lack of Progress. The American Journal of Gastroenterology, 98, 2420-2423. https://doi.org/10.1007/s100960100509

[14] Huang, J.J., Lee, W.C., Ruaan, M.K., Wang, M.C., Chang, T.T. and Young, K.C. (2001) Incidence, Transmission, and Clinical Significance of Hepatitis G Virus In- 
fection in Hemodialysis Patients. European Journal of Clinical Microbiology and Infectious Diseases, 20, 374-379.

[15] Masavkar, S.P. and Naikwadi, A.M. (2016) Knowledge, Attitude and Practice Regarding Nosocomial Infections among General Health Practitioners and Medical College Students. Scholars Journal of Applied Medical Sciences, 4, 1852-1856.

Submit or recommend next manuscript to SCIRP and we will provide best service for you:

Accepting pre-submission inquiries through Email, Facebook, LinkedIn, Twitter, etc. A wide selection of journals (inclusive of 9 subjects, more than 200 journals)

Providing 24-hour high-quality service

User-friendly online submission system

Fair and swift peer-review system

Efficient typesetting and proofreading procedure

Display of the result of downloads and visits, as well as the number of cited articles Maximum dissemination of your research work

Submit your manuscript at: http://papersubmission.scirp.org/

Or contact ijcm@scirp.org 